\title{
A Process for the Recovery of Gallium from Gallium Arsenide Scrap
}

\author{
Tsai-Hsin Cheng ${ }^{1}$, Chia-Ju Liu ${ }^{1}$, Tang-Yi Tsai ${ }^{1}$ and Yun-Hwei Shen ${ }^{2, * \mathbb{D}}$ \\ 1 Graduate Institute of Science Education and Environmental Education, National Kaohsiung Normal \\ University, Kaohsiung 80201, Taiwan; smt@lasertek.com.tw (T.-H.C.); chiaju1105@gmail.com (C.-J.L.); \\ n48011152@mail.ncku.edu.tw (T.-Y.T.) \\ 2 Department of Resources Engineering, National Cheng Kung University, Tainan 70100, Taiwan \\ * Correspondence: yhshen@mail.ncku.edu.tw
}

Received: 4 October 2019; Accepted: 26 November 2019; Published: 4 December 2019

\begin{abstract}
The recovery of gallium (Ga) from gallium arsenide (GaAs) scrap using a leaching-ion exchange method was investigated. The ground GaAs scrap was leached, using $2.0 \mathrm{~N}$ nitric acid at $30{ }^{\circ} \mathrm{C}$ for $1.0 \mathrm{~h}$, and the dissolution of $\mathrm{Ga}$ and arsenic (As) reached $98 \%$. The pregnant solution with a $1 / 20$ dilution ratio was then passed through a weak acid chelating resin Diaion CR-11. Highly charged $\mathrm{Ga}^{3+}$ has the ability to form complexes with the chelating resin and separate from the coexisting $\mathrm{H}_{3} \mathrm{AsO}_{4}$ in the leachate with very low $\mathrm{pH}$. The loaded column was eluted with $0.1 \mathrm{M} \mathrm{H}_{2} \mathrm{SO}_{4}$, and the final concentrated solution had $4.5 \mathrm{~g} / \mathrm{L}$ of Ga with $99.3 \%$ purity. The effluent from the column was further processed to remove As by ferric arsenicate precipitation, and reused continuously as the dilution water for raw leachate.
\end{abstract}

Keywords: Ga recovery; GaAs scrap; leaching-ion exchange

\section{Introduction}

In recent years, gallium $(\mathrm{Ga})$ has attracted attention in the electronics industry, as gallium arsenide (GaAs) has better electronic properties than silicon-based semiconductor materials [1]. GaAs has been extensively used in a variety of high-technology fields, such as semiconductors, infrared optics, optical fibers, medicine, and catalysis [2-5]. Gallium is considered one of the rare elements in the earth's crust, as its concentration is $16 \mathrm{ppm}$. The primary Ga metal is obtained as a byproduct of metallurgical processes in the aluminum and zinc industries. The other sources of Ga are coal fly ash [6] and the recycling of materials from scrap processing and impure metals [7-13], with $40-50 \%$ of the Ga that is consumed annually derived from recycled sources. A potential secondary source of Ga is GaAs scrap, which contains nearly $50 \%$ of the Ga wasted in the process of GaAs wafer production. More than $85 \%$ of GaAs scrap is wasted in the process of the GaAs wafer production and GaAs scrap is wasted without treatment in Taiwan. It is highly desirable to recover and recycle the valuable Ga metal and remove the toxic arsenic (As) from the GaAs scrap. There have thus been several studies on the extraction of $\mathrm{Ga}$ from GaAs scrap. Chen et al. [11] recovered Ga and As using a thermal treatment at $1000{ }^{\circ} \mathrm{C}$ for $3 \mathrm{~h}$. Although the thermal treatment completely separates $\mathrm{Ga}$ and As, the high working temperature leads to a large energy consumption. Hydrometallurgical methods have also been used to recover Ga and As. Lee and Nam [12] studied the extraction of gallium from gallium arsenide scrap and found that nitric acid is the most effective agent for the extraction of gallium, rather than hydrochloric acid or sulfuric acid. Chen et al. [14] recovered Ga and As from waste GaAs sludge by solvent extraction. The leachate of the semiconductor fabrication sludge was extracted using $\mathrm{D}_{2} \mathrm{EHPA}$ and stripped using $\mathrm{H}_{2} \mathrm{SO}_{4}$. However, the Ga extraction efficiency was only $80 \%$. Jadvar et al. [10] recovered $\mathrm{Ga}$ and $\mathrm{As}$ from GaAs wafer manufacturing slurries by leaching and evaporation. The 
process has five washing steps and seven settling steps, which consume a large amount of water and time. These drawbacks mentioned above could increase the cost and decrease the feasibility for $\mathrm{Ga}$ and As recovery. One promising method to recover Ga from the leaching solution is ion exchange, a highly effective and economical approach. The purpose of this study is thus to develop a process using leaching-ion exchange to recover $\mathrm{Ga}$ and remove the toxic As from GaAs scrap.

\section{Materials and Methods}

\subsection{Analysis of GaAs Scrap}

The GaAs scrap used in this study was obtained from an electronics company in southern Taiwan. The GaAs scrap was ground and sieved using a 100-mesh sieve. An X-ray diffractometer (XRD-RAPID II, Rigaku, Woodlands, TX, USA) was used to examine the crystalline phases of the sample. A $0.1 \mathrm{~g}$ ground sample was digested using aqua regia at $100{ }^{\circ} \mathrm{C}$ for $30 \mathrm{~min}$. After cooling and filtration, the composition of the filtrate was determined using atomic absorption spectroscopy (AAS, Varian AA240, Palo Alto, CA, USA) with an air-acetylene flame. All the analyses were run in duplicate and the mean values were considered. The results were found to vary within $3 \%$. The $X$-ray diffraction pattern of the sample is shown in Figure 1, and the typical chemical composition of the sample is shown in Table 1. The AAS analysis results showed that the Ga content was 38\% and that of As was $49 \%$.

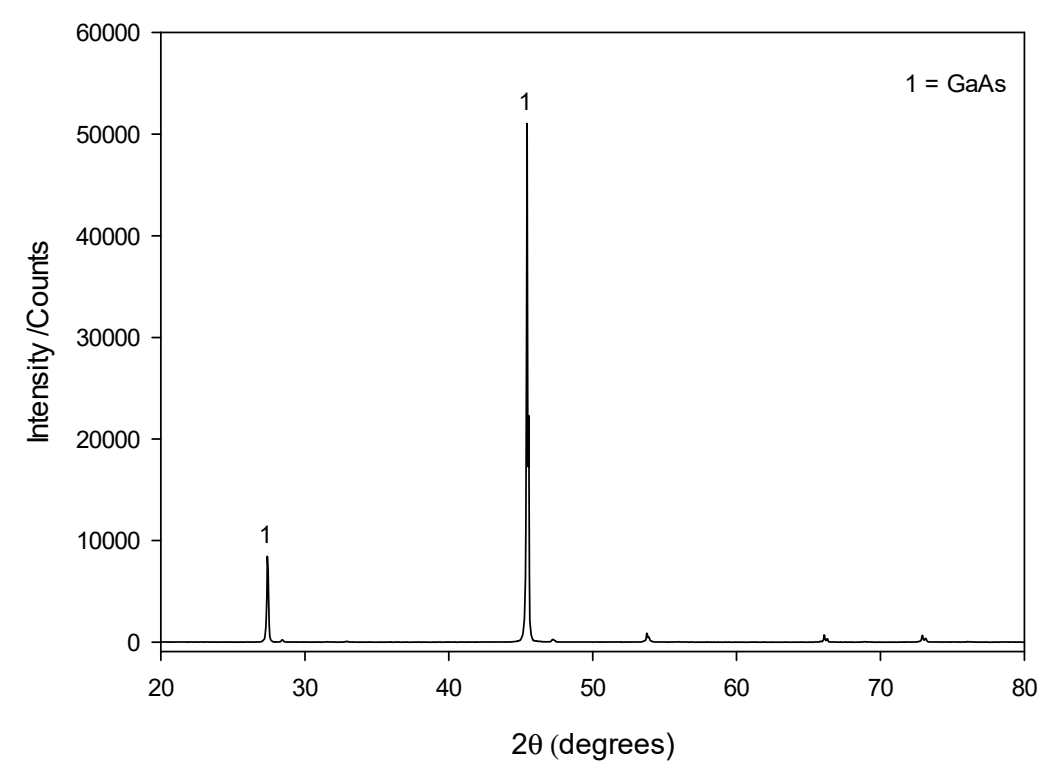

Figure 1. X-ray diffraction analysis of the GaAs scrap sample.

Table 1. Chemical analysis of gallium arsenide scrap

\begin{tabular}{cccccc}
\hline Ga (\%) & As (\%) & $\mathbf{P ~ ( \% ) ~}$ & In (\%) & Sn (\%) & Mg (\%) \\
\hline 38 & 49 & 9 & 1 & 1 & 1 \\
\hline
\end{tabular}

\subsection{Leaching of $\mathrm{Ga}$ and $A s$}

As reported by Lee and Nam [12], $\mathrm{HNO}_{3}$ is the most effective acid for the extraction of Ga from GaAs scrap. Different experimental conditions, such as acid concentration, solid/liquid (S/L) ratio, leaching time, and temperature, were investigated. The leaching tests were carried out at atmospheric pressure in a Pyrex stirred reactor placed in a heated water bath. After leaching, the solution was filtrated and analyzed using AAS. The dissolution percentages of Ga and As were calculated. The filtrate was collected and used in the ion exchange experiments of this work. 


\subsection{Ion Exchange Separation of $G a$ and $A s$}

\subsubsection{Resin}

We examined several commercial resins for their suitability for this separation at low $\mathrm{pH}$. A commercial weak acid chelating resin, Diaion CR-11 (Mitsubishi Chemical, Tokyo, Japan), appears to be very promising for this purpose. This resin is characterized by the iminodiacetate acid functional group, as shown in Figure 2. With this, the metal ions can bind with one nitrogen and two oxygen atoms at the most. The resin obtained in the sodium form was used directly in this study.

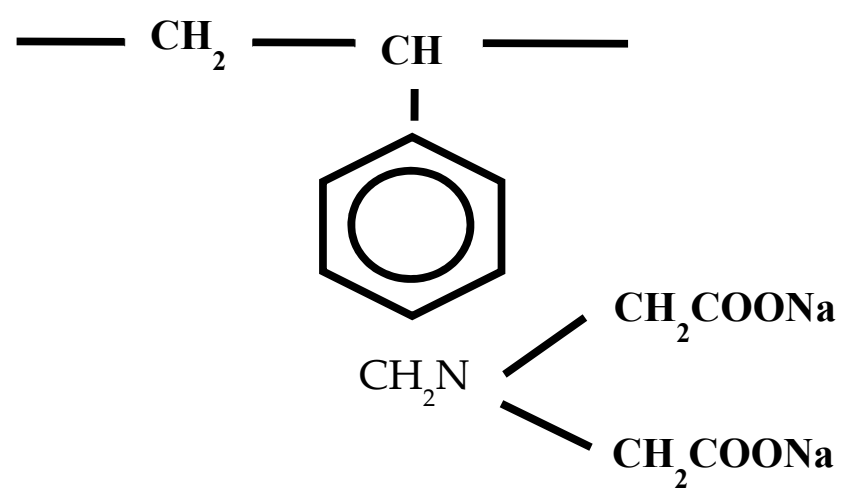

Figure 2. Chemical structure of Diaion CR-11 chelating resin.

\subsubsection{Column Experiments}

The separation of Ga from the leached GaAs scrap solution with the resin CR-11 was carried out in a column test. Next, $5.4 \mathrm{~mL}$ of wet-settled resin was packed into a glass column with a length $\mathrm{of} 10 \mathrm{~cm}$ and a diameter of $5 \mathrm{~mm}$. The original and pre-diluted leachate was passed through the column by downstream flow at a constant flow rate of $0.1 \mathrm{~mL} / \mathrm{min}$. The samples were collected periodically from the column effluent and analyzed to determine the $\mathrm{Ga}$ and As concentrations. The loaded resin was eluted with $\mathrm{H}_{2} \mathrm{SO}_{4}$ by the downstream flow at the flow rate of $0.1 \mathrm{~mL} / \mathrm{min}$. The $\mathrm{Ga}$ and As contents in the feeds and effluents were analyzed using AAS. The exchange capacity and distribution, as well as the separation ratio, were calculated from the analytical data. The separation factors of Ga and As are defined as the ratio of the distribution of the Ga ions between the resin phase and the solution phase to that of the As ions.

\subsection{As Removal Experiments}

As removal experiments were carried out with the effluents collected from the column test runs containing $746 \mathrm{mg} / \mathrm{L}$ of As. A fixed amount of $\mathrm{Fe}_{2}\left(\mathrm{SO}_{4}\right)_{3}$ was added to each of a series $100 \mathrm{~mL}$ beakers containing $50 \mathrm{~mL}$ As solution to achieve an Fe/As molar ratio of 3.6, and this was stirred at $100 \mathrm{rpm}$ with a magnetic stirrer. Various dosages of the $2-\mathrm{M} \mathrm{NaOH}$ solution were then successively added while stirring for a further $10 \mathrm{~min}$. The mixture was let to stand overnight to allow the solids to settle, and then it was filtered for the filtrate and sludge separation. The residual As concentration in the filtrate was determined by AAS. The main mineral phases of the sludge were identified by the XRD analysis.

\section{Results and Discussion}

\subsection{Leaching of $G a$ and As}

Table 2 shows the extraction efficiencies of $\mathrm{Ga}$ and $\mathrm{As}$ with $\mathrm{HNO}_{3}$ using various acid concentrations, solid/liquid (S/L) ratios, and leaching times with a constant stirring speed at $30^{\circ} \mathrm{C}$. The percentages of the recovered Ga were $12 \%, 83 \%, 98 \%$, and $99 \%$, and the percentages of the recovered As were $13 \%$, $81 \%, 98 \%$, and $98 \%$ using $1,1.5,2.0$, and $4.0 \mathrm{~N} \mathrm{HNO}_{3}$, respectively. Ga and As were almost completely 
extracted using $2 \mathrm{~N} \mathrm{HNO}_{3}$. The effects of the $\mathrm{S} / \mathrm{L}$ ratio on the extraction efficiencies for $\mathrm{Ga}$ and As using $2 \mathrm{~N} \mathrm{HNO}_{3}$ with a constant stirring speed at $30{ }^{\circ} \mathrm{C}$ for $2 \mathrm{~h}$ are shown in Table 2 . The percentages of the recovered Ga were $98 \%, 81 \%$, and $65 \%$, and the percentages of recovered As were $98 \%, 84 \%$, and $76 \%$ using the $\mathrm{S} / \mathrm{L}$ ratio of $2 \mathrm{~g} / 100 \mathrm{~mL}, 4 \mathrm{~g} / 100 \mathrm{~mL}$, and $6 \mathrm{~g} / 100 \mathrm{~mL}$, respectively. Therefore, an increase in the $\mathrm{S} / \mathrm{L}$ ratio significantly affected the degree of leaching of $\mathrm{Ga}$ and As. The optimal recoveries of $\mathrm{Ga}$ and As occurred with a S/L ratio of $2 \mathrm{~g} / 100 \mathrm{~mL}$. The leaching durations of $1 \mathrm{~h}$ and $2 \mathrm{~h}$ were tested using the same conditions as those for the former experiment, and the GaAs scrap was completely dissolved after $2 \mathrm{~h}$ (see Table 2). The optimal leaching conditions were $2.0 \mathrm{~N}$ of $\mathrm{HNO}_{3}, \mathrm{~S} / \mathrm{L}$ of $2 \mathrm{~g} / 100 \mathrm{~mL}$, and $30{ }^{\circ} \mathrm{C}$ for $1.0 \mathrm{~h}$, which yielded dissolution percentages for Ga and As of $98 \%$ each. The filtered leachate was collected and used in the ion exchange experiments.

Table 2. Extraction efficiencies of $\mathrm{Ga}$ and As using various $\mathrm{HNO}_{3}$ concentrations, solid/liquid ratio, and leaching time with a constant stirring speed at $30^{\circ} \mathrm{C}$

\begin{tabular}{cccccc}
\hline $\begin{array}{c}{\left[\mathrm{HNO}_{3}\right]} \\
\mathbf{( N )}\end{array}$ & $\begin{array}{c}\text { Temp } \\
{ }^{\circ} \mathbf{C}\end{array}$ & $\begin{array}{c}\text { S/L } \\
(\mathbf{g} / \mathbf{1 0 0} \mathbf{~ m L})\end{array}$ & $\begin{array}{c}\text { Time } \\
(\mathbf{h})\end{array}$ & $\begin{array}{c}\text { Ga Leached } \\
(\mathbf{\%})\end{array}$ & $\begin{array}{c}\text { As Leached } \\
(\mathbf{\%})\end{array}$ \\
\hline 1.0 & 30 & 2 & 2 & 12 & 13 \\
1.5 & 30 & 2 & 2 & 83 & 81 \\
2.0 & 30 & 2 & 2 & 98 & 98 \\
4.0 & 30 & 2 & 2 & 99 & 98 \\
2.0 & 30 & 4 & 2 & 81 & 84 \\
2.0 & 30 & 6 & 2 & 65 & 76 \\
2.0 & 30 & 2 & 1 & 85 & 85 \\
\hline
\end{tabular}

\subsection{Ion Exchange Separation of $\mathrm{Ga}$ and As}

The leachate consisting of 12,600-ppm Ga and 19,000-ppm As at $\mathrm{pH}<0$, was used in the ion exchange experiments. Because of the extremely acidic nature of the collected leachate, a dilution procedure was applied prior to the column experiments. In the column experiments, the leachates with different dilution ratios $(1 / 5,1 / 10,1 / 20$, and $1 / 40)$ were passed through the column packed with the CR-11 resins at a constant flow rate. The breakthrough curves were plotted as a dimensionless concentration factor $C / C_{0}$ versus a dimensionless effluent volume (bed volume, BV). Figures 3 and 4 show the breakthrough and elution curves for Ga and As, respectively, present in the leach solutions with different dilution ratios during resin loading. It was observed in all the results that the iminodiacetic acid chelating resin Diaion CR-11 preferred the Ga ions. At very low $\mathrm{pH}, \mathrm{Ga}$ existed as a cationic species of $\mathrm{Ga}^{3+}$ and As existed as a neutral species of $\mathrm{H}_{3} \mathrm{AsO}_{4}$ [15]. Furthermore, at very low $\mathrm{pH}$, the carboxylic and amine groups were fully pronated [16], and in order that cations could form complexes with the CR-11 resin, the resin should be found in the deprotonated form. However, highly charged $\mathrm{Ga}^{3+}$ had the ability to displace the protons from the carboxylic or amine groups, and they could form complexes at very low $\mathrm{pH}$. Ga ${ }^{3+}$ was thus adsorbed and separated from the coexisting $\mathrm{H}_{3} \mathrm{AsO}_{4}$ at low $\mathrm{pH}$ with the Diaion CR-11 resin, on the basis of the mechanism illustrated in Figure 5. It can be seen in Figure $3 a$ that when the dilution ratio was varied from $1 / 5$ to $1 / 40$, the breakthrough point changed from $2 \mathrm{BV}$ to $50 \mathrm{BV}$. A lower dilution ratio resulted in a higher Ga concentration in the influent, which led to the faster saturation of resin and the earlier effusion of $\mathrm{Ga}$. In the elution experiments, the elution was conducted immediately after the completion of the loading experiment. Figure $3 \mathrm{~b}$ or Figure $4 \mathrm{~b}$ show the elution curves for $\mathrm{Ga}$ and As, respectively. We observed that $\mathrm{Ga}$ could be effectively eluted by the $0.1-\mathrm{N} \mathrm{H}_{2} \mathrm{SO}_{4}$ solution at an eluent flow rate of $0.1 \mathrm{~mL} / \mathrm{min}$, and the complete elution occurred after $6 \mathrm{BV}$ passed through the column. The exchange capacity ( $\mathrm{mg} \mathrm{Ga} / \mathrm{mL}$ resin), as well as the distribution and the separation ratio, was calculated from the analytical data. The distribution ratio was calculated from the milligrams of metal adsorbed per $\mathrm{ml}$ of the resin divided by the milligrams of metal per milliliter of solution, and the separation factor was calculated from the distribution ratio of each metal, with the results for both shown in Table 3. The table shows that the dilution ratio had an effect on the Ga exchange capacity. With the dilution increasing from $1 / 5$ to $1 / 40$, the Ga exchange capacity increased 
from 9.6 to $26.3 \mathrm{mg} \mathrm{Ga} / \mathrm{mL}$ resin. It was thus obvious that the dilution of the leachate was advantageous for the Ga adsorption onto the resin. However, the dilution increased the consumption of water, and required a large volume of leachate to be processed, raising issues with the use of this procedure. The dilution ratio of $1 / 20$ was an intermediate value in our experiments and resulted in a relatively high Ga exchange capacity $\left(25.7 \mathrm{mg}_{\mathrm{Ga}} / \mathrm{mL}_{\text {resin }}\right)$ compared to that of $11.8 \mathrm{mg}_{\mathrm{Ga}} / \mathrm{mL}_{\text {resin }}$ for a ratio of $1 / 10$ on resin. In addition, the $\mathrm{Ga} / \mathrm{As}$ separation factor and the $\mathrm{Ga} / \mathrm{As}$ mass ratio for the Ga concentrate could reach 115 and 105, respectively, at the 1/20 dilution. In order to selectively concentrate Ga with the iminodiacetic acid chelating resin Diaion CR-11, it is suggested that the loading stage be carried out using a feed solution of a $1 / 20$ dilution with a flow rate of $1.0 \mathrm{BV} / \mathrm{h}$, and that the feed be stopped after $35 \mathrm{BV}$. The adsorbed Ga could then be eluted with 0.1- $\mathrm{M} \mathrm{H}_{2} \mathrm{SO}_{4}$ and an eluent solution flow rate of $1.0 \mathrm{BV} / \mathrm{h}$ (Figure $3 \mathrm{~b}$ or Figure $4 \mathrm{~b}$ ). Under these experimental conditions, the final concentrated solution had $4.5 \mathrm{~g} / \mathrm{L}$ of $\mathrm{Ga}\left(\mathrm{as} \mathrm{Ga}_{2}\left(\mathrm{SO}_{4}\right)_{3}\right)$ with $99.3 \%$ purity. High-grade $\mathrm{Ga}$ might be produced by the electrolysis of the solution obtained. In practical operations, it is required that the columns be used repeatedly. Therefore, the $\mathrm{Ga} / \mathrm{As}$ separation behavior of the resin was tested by repeating the loading and elution for three cycles. The results from the cycling experiments are presented in Table 4 . As can be seen, almost identical exchange capacity, as well as the distribution and the separation ratio were obtained for each individual cycle and no appreciable deterioration in loading and elution behavior was observed.

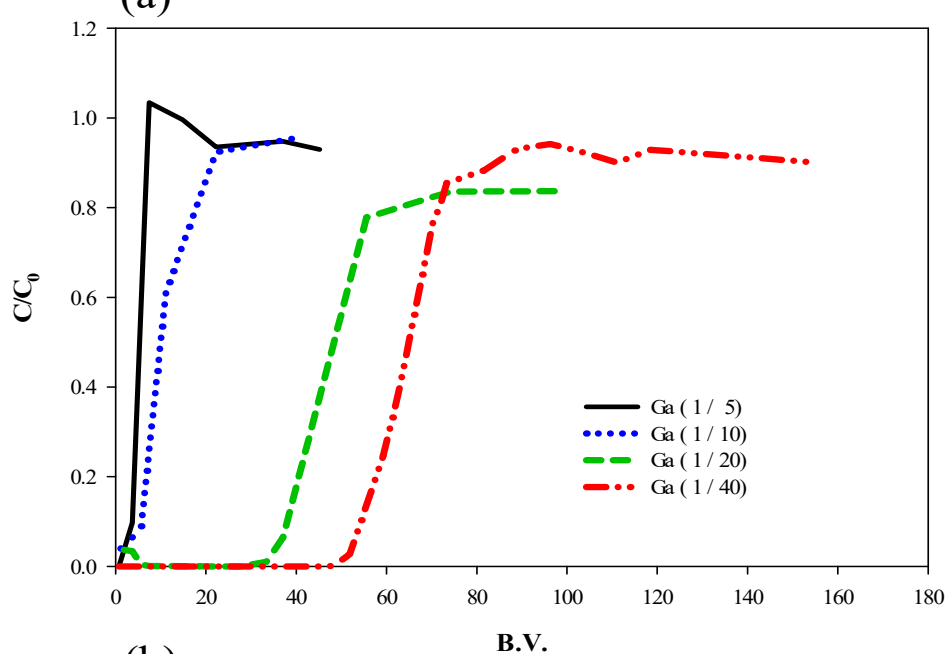

(b)

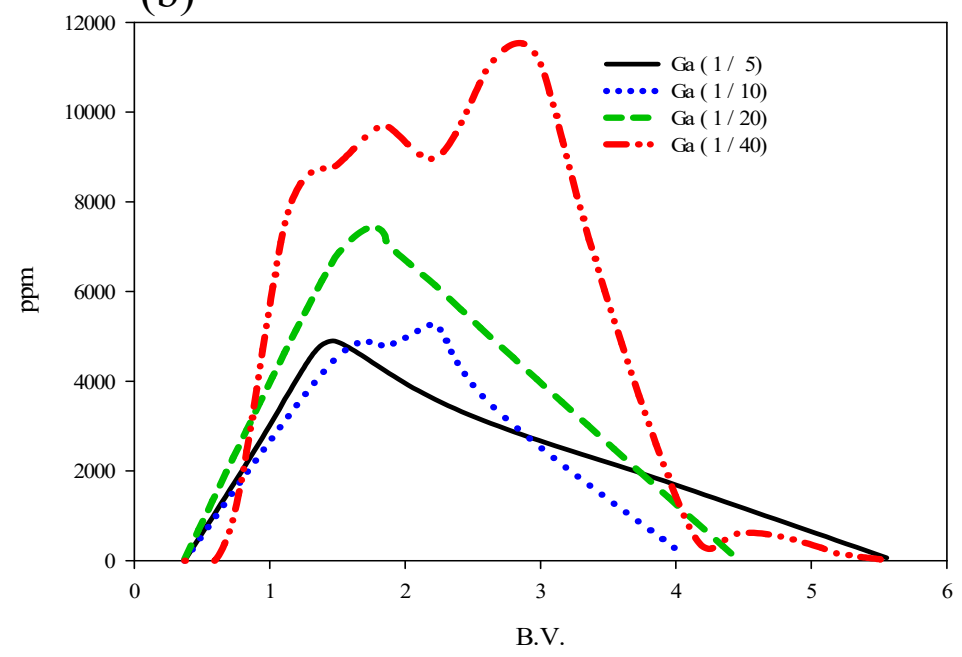

Figure 3. Breakthrough (a) and elution (b) curves for Ga in solutions with different dilution ratios. 
(a)

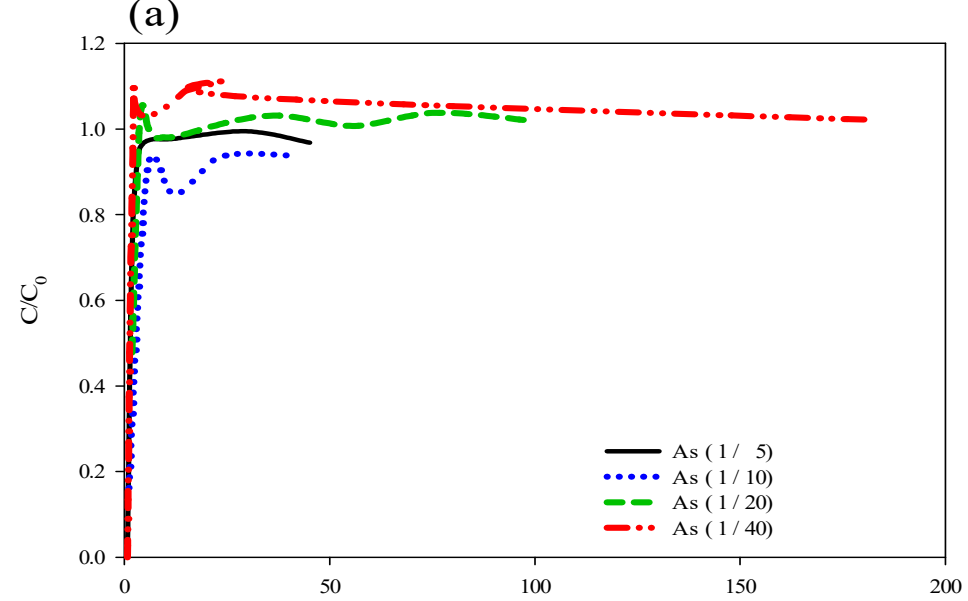

(b)

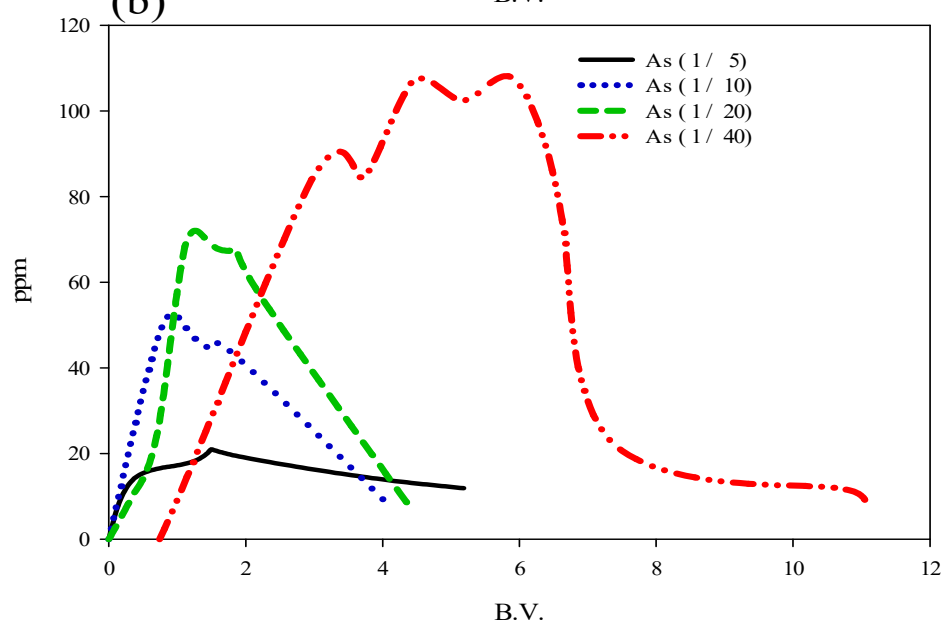

Figure 4. Breakthrough (a) and elution (b) curves for As in solutions with different dilution ratios.

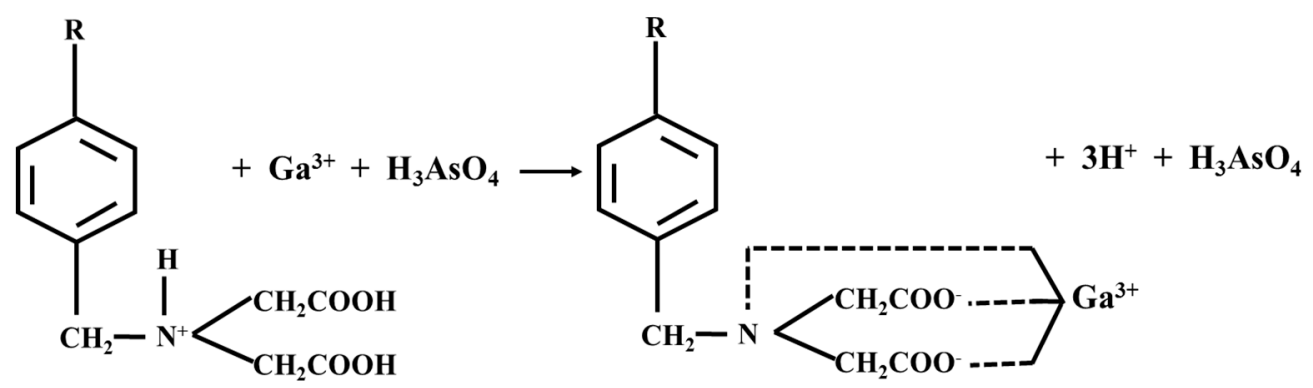

Figure 5. Proposed mechanism for the adsorption of $\mathrm{Ga}^{3+}$ by Diaion $\mathrm{CR}-11$ resin.

Table 3. Mass balance of Ga and As for column loading experiments

\begin{tabular}{ccccc}
\hline $\begin{array}{c}\text { Dilution } \\
\text { Ratio }\end{array}$ & $\begin{array}{c}\text { Ga-Exchange } \\
\text { Capacity } \\
\text { (mg/mL Resin) }\end{array}$ & $\begin{array}{c}\text { As-Exchange } \\
\text { Capacity } \\
\text { (mg/mL Resin) }\end{array}$ & $\begin{array}{c}\text { Ga/As Separation } \\
\text { Factor }\end{array}$ & $\begin{array}{c}\text { Ga/As Mass Ratio } \\
\text { for Ga } \\
\text { Concentrate }\end{array}$ \\
\hline $1 / 5$ & 9.6 & 0.08 & 120 & 121 \\
$1 / 10$ & 11.8 & 0.13 & 116 & 103 \\
$1 / 20$ & 25.7 & 0.24 & 115 & 155 \\
$1 / 40$ & 26.3 & 0.27 & 109 & 140 \\
\hline
\end{tabular}


Table 4. Results of loading/elution cycling experiments from Diaion CR-11 resin

\begin{tabular}{ccccc}
\hline Cycle & $\begin{array}{c}\text { Ga-Exchange } \\
\text { Capacity } \\
\text { (mg/mL Resin) }\end{array}$ & $\begin{array}{c}\text { As-Exchange } \\
\text { Capacity } \\
\text { (mg/mL Resin) }\end{array}$ & $\begin{array}{c}\text { Ga/As Separation } \\
\text { Factor }\end{array}$ & $\begin{array}{c}\text { Ga/As Mass Ratio } \\
\text { for Ga } \\
\text { Concentrate }\end{array}$ \\
\hline 1 & 25.7 & 0.24 & 115 & 155 \\
2 & 23.9 & 0.22 & 116 & 155 \\
3 & 25.5 & 0.22 & 117 & 155 \\
\hline
\end{tabular}

\subsection{As Removal Experiments}

A significant amount of the As-containing (746-ppm As) effluent was produced after ion exchange because of the high dilution ratio $(1 / 20)$ used to dilute the raw leachate. This raises concerns with regard to the environmental pollution, as well as the high consumption of water. The removal of As by the ferric arsenicate precipitation and the reuse of the effluent as the dilution water for the leachate were thus examined. The results of the preliminary tests indicated that an Fe:As molar ratio of 3.6 yielded an optimum result in terms of the As removal and the volume of ferric arsenate precipitated. The As removal efficiency as a function of the precipitation $\mathrm{pH}$ at a $\mathrm{Fe} / \mathrm{As}$ ratio of 3.6 is shown in Figure 6. The $\mathrm{pH}$ for maximum removal was found to be 6 , and the corresponding minimum As concentration was $50 \mathrm{mg} / \mathrm{L}$. The precipitated residue produced at $\mathrm{pH} 6$ was analyzed using XRD, to identify the crystalline phase. The results showed that the major phases were $\mathrm{Fe}_{4} \mathrm{O}_{3}\left(\mathrm{AsO}_{4}\right)_{2}$ and $\mathrm{Fe}_{2} \mathrm{O}_{3}$ (see Figure 7). The result of the TCLP for the precipitate was $1.5 \mathrm{ppm}$, which was lower than the regulative limit for As (5 ppm) in Taiwan. Therefore, the precipitation process decreased the leaching potential of As under acidic conditions and reduced the impact on the environment. The elimination of As would render the effluent reusable after ion exchange and it could then be reused continuously as the dilution water for raw leachate, and the feasibility of this approach was examined, with the results shown in Figure 8. Figure 8 shows a comparison of the normalized breakthrough curves when loading the column with the leachate diluted with reused or fresh water. It was clear that the use of reused water had no influence on the Ga loading behavior for using the reused water, and thus, the water consumption in this process could be minimized significantly.

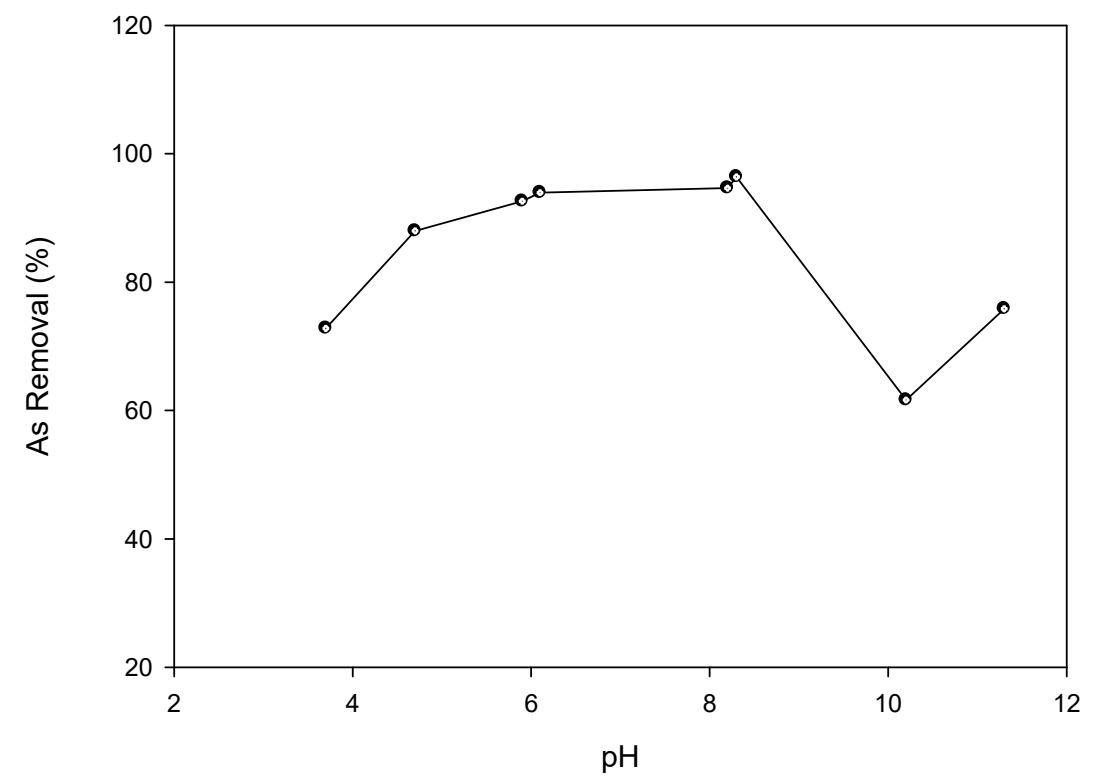

Figure 6. As removal efficiency as a function of precipitation $\mathrm{pH}$ at a $\mathrm{Fe} / \mathrm{As}$ ratio of 3.6. 


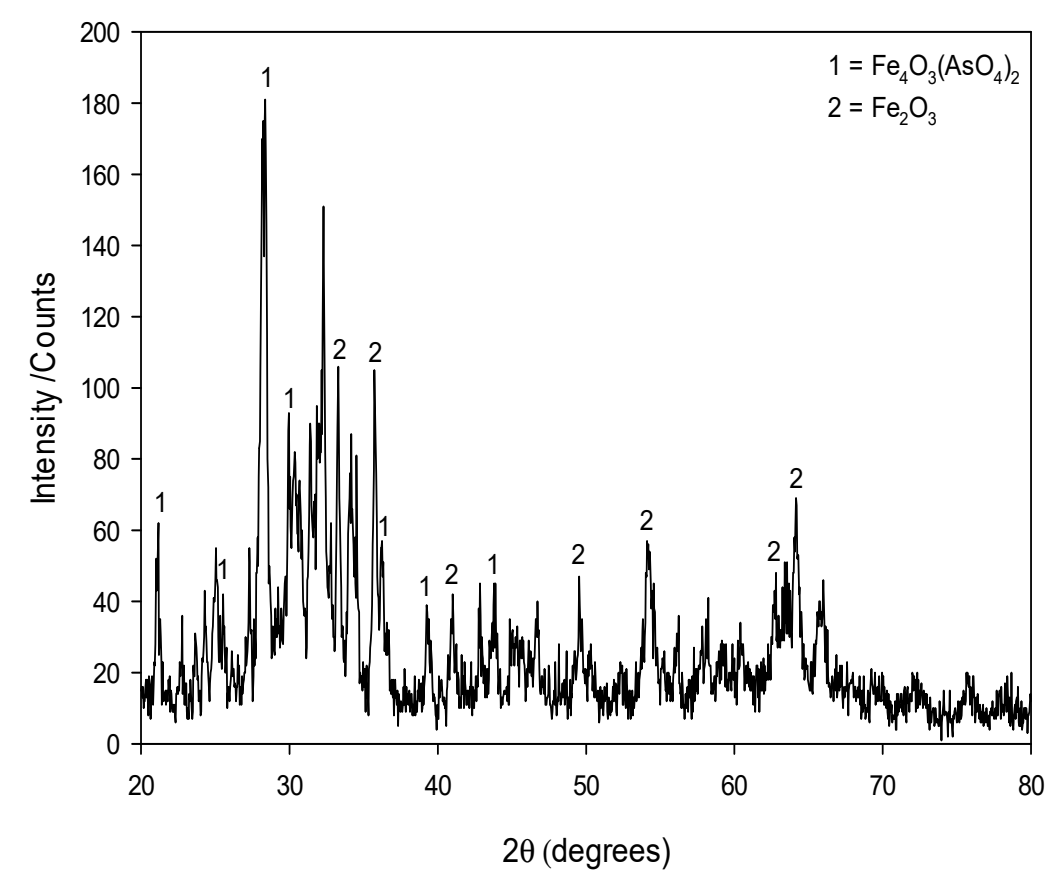

Figure 7. X-ray diffraction analysis of the precipitated residue.

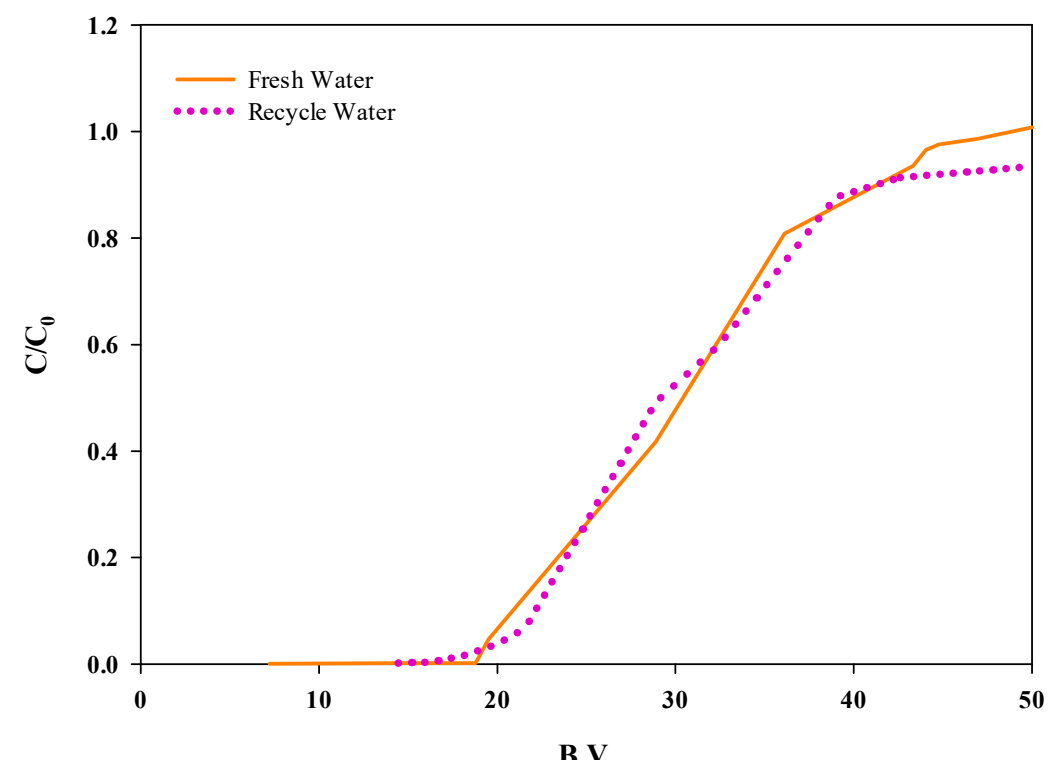

Figure 8. Breakthrough curves for loading the column with leachate dilution with reused and fresh water.

\subsection{Recommended Process for Recovery of $\mathrm{Ga}$}

A recommended process for leaching Ga from GaS scrap and its selective recovery from the leached solution using CR-11 resin is summarized in Figure 9. A 2.0- $\mathrm{N} \mathrm{HNO}_{3}$ solution was mixed with the scrap sample at an $\mathrm{S} / \mathrm{L}$ of $2 \mathrm{~g} / 100 \mathrm{~mL}$ and then leached at $30^{\circ} \mathrm{C}$ for $1.0 \mathrm{~h}$. The pregnant solution with a $1 / 20$ dilution ratio was then passed through the resin. The loaded column was eluted with $0.1-\mathrm{M} \mathrm{H}_{2} \mathrm{SO}_{4}$ and the concentrated $\mathrm{Ga}\left(\mathrm{as} \mathrm{Ga}_{2}\left(\mathrm{SO}_{4}\right)_{3}\right)$ solution was collected. The effluent from the column was further processed to remove As by ferric arsenicate precipitation and reused continuously as the dilution water for the raw leachate. In addition, the As removed filtrate contained significant amounts of nitrate anions which carried-over to recycled water; this is an undesirable aqueous stream contamination problem. To remove nitrate, the As removed filtrate was purified by a conventional membrane method $[17,18]$. 


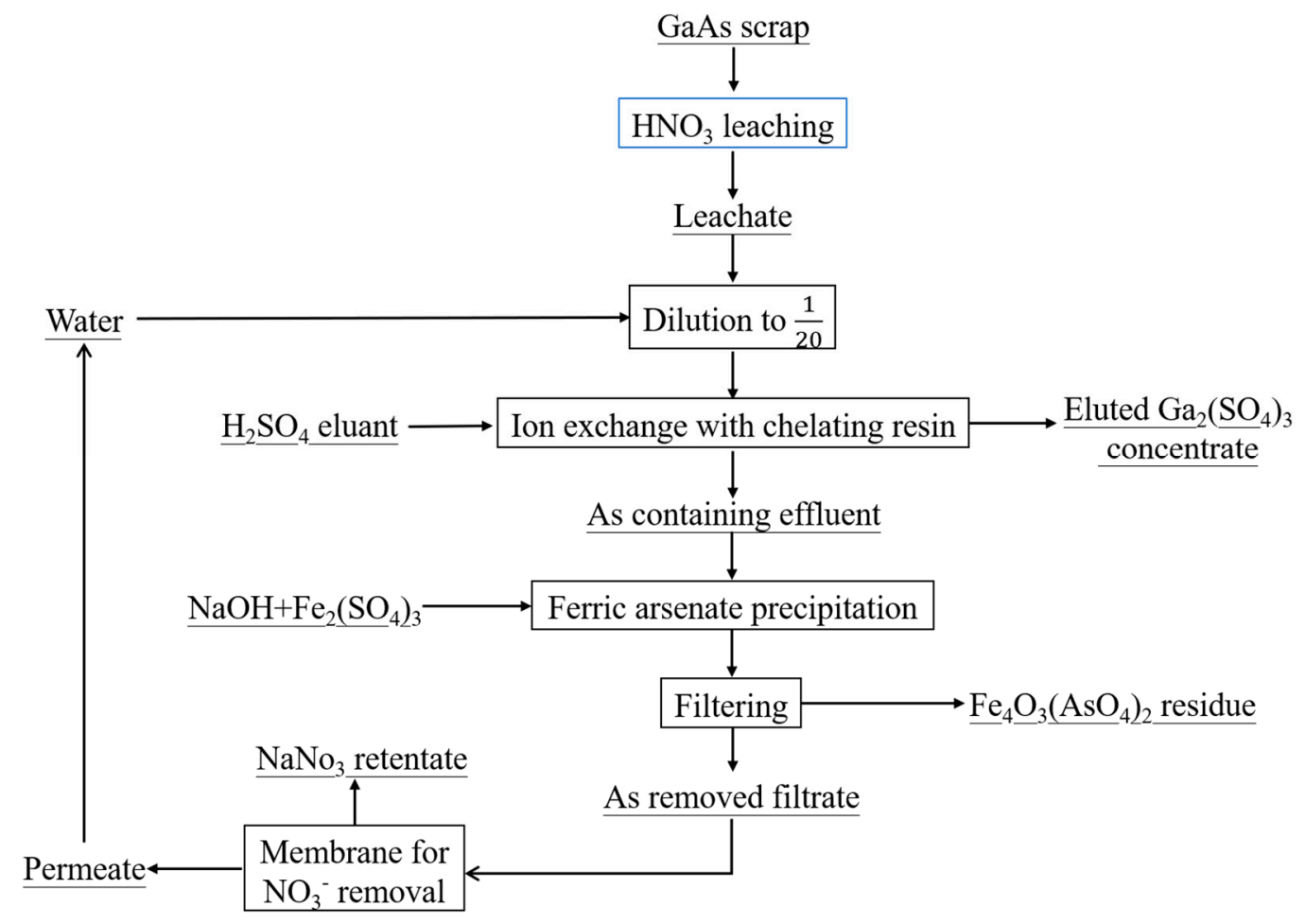

Figure 9. Proposed flow chart for the recovery of Ga from GaAs scrap.

\section{Conclusions}

Studies were performed to develop a process using a leaching-ion exchange method to recover Ga from the GaAs scrap. According to the results obtained, the following conclusions were drawn: The optimal leaching conditions were as follows: $2.0 \mathrm{~N}$ of $\mathrm{HNO}_{3}, \mathrm{~S} / \mathrm{L}$ of $2 \mathrm{~g} / 100 \mathrm{~mL}$, and $30^{\circ} \mathrm{C}$ for $1.0 \mathrm{~h}$, which yielded the dissolution percentage of $98 \%$ for both Ga and As. Highly charged Ga ${ }^{3+}$ ions have the ability to form complexes with the iminodiacetic acid chelating resin Diaion CR-11 and separate from the coexisting $\mathrm{H}_{3} \mathrm{AsO}_{4}$ at very low $\mathrm{pH}$. It was suggested that, the loading stage be carried out using a feed solution of $1 / 20$ dilution with a flow rate of $1.0 \mathrm{BV} / \mathrm{h}$ and by stopping the feed after $35 \mathrm{BV}$. The adsorbed Ga could then be eluted with $0.1 \mathrm{M} \mathrm{H}_{2} \mathrm{SO}_{4}$ and an eluent solution flow rate of $1.0 \mathrm{BV} / \mathrm{h}$. The final concentrated $\mathrm{Ga}\left(\mathrm{as} \mathrm{Ga}_{2}\left(\mathrm{SO}_{4}\right)_{3}\right)$ solution had $4.5 \mathrm{~g} / \mathrm{L}$ of $\mathrm{Ga}$ with $99.3 \%$ purity. The effluent from the column was further processed to remove As by ferric arsenicate precipitation and reused continuously as the dilution water for the raw leachate. The maximum arsenic removal of $95 \%$ was achieved at $\mathrm{pH} 6$ by using an Fe/As ratio of 3.6. The proposed leaching-ion exchange method allowed the feasible recovery of Ga from GaAs scrap and provided a new approach for the comprehensive utilization of this material.

Author Contributions: T.-H.C. and T.-Y.T. performed the experiments and analyzed and interpreted the data. C.-J.L. contributed to interpretation of the data. Y.-H.S. was the Principal Investigator of this work and edited the paper.

Funding: This research was supported by a grant (No. 05T6D0020E) from the China Steel Corporation (CSC).

Conflicts of Interest: The authors declare no conflict of interest.

\section{References}

1. Moskalyk, R.R. Gallium: The backbone of the electronics industry. Miner. Eng. 2003, 16, 921-929. [CrossRef]

2. Schimmel, R.C.; Faber, A.J.; De, W.H.; Beerkens, R.G.C.; Khoe, G.D. Development of germanium gallium sulphide glass fibres for the $1.31 \mu \mathrm{m}$ praseodymium-doped fibre amplifier. J. Non-Cryst. Solids 2001, 284, 188-192. [CrossRef] 
3. Fujiwara, M.; Hirao, T.; Kawada, M.; Shibai, H.; Matsuura, S.; Kaneda, H.; Patrashin, M.; Nakagawa, T. Development of a gallium-doped germanium far-infrared photoconductor direct hybrid two-dimensional array. Appl. Opt. 2003, 42, 2166-2173. [CrossRef] [PubMed]

4. Depuydt, B.; Theuwis, A.; Romandic, I. Germanium: From the first application of Czochralski crystal growth to large diameter dislocation-free wafers. Mater. Sci. Semicond. Process. 2006, 9, 437-443. [CrossRef]

5. Tyszczuk, K.; Korolczuk, M.; Grabarczyk, M. Application of galliumfilm electrode for elimination of copper interference in anodic stripping voltammetry of zinc. Talanta 2007, 71, 2098-2101. [CrossRef] [PubMed]

6. Fang, Z.; Gesser, H.D. Recovery of gallium from coal fly ash. Hydrometallurgy 1996, 41, 187-200. [CrossRef]

7. Puvvada, G.V.K. Liquid-liquid extraction of gallium from Bayer process liquor using Kelex 100 in the presence of surfactants. Hydrometallurgy 1999, 52, 9-19. [CrossRef]

8. Kinoshita, T.; Akita, S.; Nii, S.; Kawaizumi, F.; Takahashi, K. Solvent extraction of gallium with non-ionic surfactants from hydrochloric acid solution and its application to metal recovery from zinc refinery residues. Sep. Purif. Technol. 2004, 37, 127-133.

9. Bina, G.; Niti, M.; Zareena, B.I.; Indu, S. Extraction and recovery of gallium (III) from waste material using Cyanex 923. Hydrometallurgy 2007, 87, 18-26.

10. Jadvar, R.; McCoy, B.J.; Ford, B.; Galt, J. Recovery of gallium and arsenic from GaAs wafer manufacturing slurries. Environ. Prog. 1991, 10, 278-281.

11. Chen, W.T.; Tsai, L.C.; Tsai, F.C.; Shu, C.M. Recovery of gallium and arsenic from gallium arsenide waste in the electronic industry. CLEAN Soil Air Water 2012, 40, 531-537. [CrossRef]

12. Lee, H.S.; Nam, C.W. A study on the extraction of gallium from gallium arsenide scrap. Hydrometallurgy 1998, 49, 125-133. [CrossRef]

13. Sturgill, J.A.; Swartzbaugh, J.T.; Randall, P.M. Pollution prevention in the semiconductor industry through recovery and recycling of gallium and arsenic from GaS polishing wastes. Clean Prod. Proc. 2000, 2, 18-27. [CrossRef]

14. Chen, W.T.; Chu, Y.C.; Wei, J.M.; Tsai, L.C.; Tsai, F.C.; Lin, C.P.; Shu, C.M. Gallium and arsenic recovery from waste gallium arsenide by wet refined methods. Adv. Mater. Res. 2011, 194, 2115-2118. [CrossRef]

15. Pourbaix, M. Atlas of Electrochemical Equilibria in Aqueous Solutions, 2nd ed.; Natl Assn of Corrosion Engineers: Houston, TX, USA, 1974; pp. 155-162.

16. Zainol, Z.; Nicol, M.J. Ion-exchange equilibria of $\mathrm{Ni}^{2+}, \mathrm{Co}^{2+}, \mathrm{Mn}^{2+}$, and $\mathrm{Mg}^{2+}$ with iminodiacetic acid chelating resin Amberlite IRC 748. Hydrometallurgy 2009, 99, 175-180. [CrossRef]

17. Gao, Q.; Wang, C.Z.; Liu, S.; Hanigan, D.; Liu, S.T.; Zhao, H.Z. Ultrafiltration membrane micro reactor (MMR) for simultaneous removal of nitrate and phosphate from water. Chem. Eng. J. 2019, 355, 238-246. [CrossRef]

18. Mukherjee, R.; De, S. Adsorptive removal of nitrate from aqueous solution by polyacrylonitrile-alumina nanoparticle mixed matrix hollow-fiber membrane. J. Membr. Sci. 2014, 466, 281-292. [CrossRef] 